\title{
An Exploration on the Effective Factors of Tourism Industry on Protection of the Environment in the Historical City Ghoumas
}

\author{
Hooman Mesgarian ${ }^{1}$, Leili Alaei ${ }^{2}$ \\ ${ }^{1}$ Department of Geography, Islamic Azad University, Semnan Branch, Member of Young Researchers Elite Club, \\ Semnan, Iran \\ ${ }^{2}$ Department of Architecture, Islamic Azad University, Savadkooh Branch, Savadkooh, Iran \\ Email: ${ }^{*}$ mesgarian.eng@gmail.com
}

Received 14 April 2014; revised 20 May 2014; accepted 4 June 2014

Copyright (C) 2014 by authors and Scientific Research Publishing Inc.

This work is licensed under the Creative Commons Attribution International License (CC BY).

http://creativecommons.org/licenses/by/4.0/

(c) (i) Open Access

\begin{abstract}
According to the world tourism organization (WHO) in 2005, the number of tourists has increased up to 36 times. In a way that it has maximized from 25 million in 1950 to 1018 million in 2010. The sustainable tourism, thus, because of making a balance between different environmental, economic, cultural and social dimensions of the tourism development, plays a considerable role in protection of species diversity, and benefits the tourism activists in order to reduce its destructive impact on the environment and the local cultures and being kept for the future generations. Accordingly, the present research first examines the relationship between tourism, sustainable development and the ecology, for measurement of different aspects of the industry effect on the environment. Secondly, the present study uses from some parameters like the average monthly minimum and maximum temperatures, the average relative humidity, the average maximum and minimum temperatures in day and at night in the Semnan station as well as using the common diagram in the experimental methods like Olegi to assess day and night Climatourism in the region. Finally, on the basis of the performed analysis, the strengths and weak points of tourist attractions for the protection of the environment are considered.
\end{abstract}

\section{Keywords}

Climatourism, Semnan, Sustainable Development, The Environment, Tourism

\section{Introduction}

The tourism industry as one of leading industries including hotel, restaurants, the domestic and international "Corresponding author.

How to cite this paper: Mesgarian, H. and Alaei, L. (2014) An Exploration on the Effective Factors of Tourism Industry on Protection of the Environment in the Historical City Ghoumas. Open Journal of Ecology, 4, 582-589. 
transportation and handcrafts has played a considerable role. According to the data reported by World Tourism Organizations (WTO), the tourism industry in 2005 cost 6.2 trillion dollars [1]. In the world today, tourism has been recognized as a factor for improvement of quality of life in the developing countries. Sustainable development, in fact, due to its ability in making a balance between ecological economic and cultural dimensions of tourism development is highly effective in protection of species diversity. The tourism industry struggles to create jobs, make money and benefit the activist in this industry and reduces its destructive effects on the environment and the local cultures to be preserved for the future generations. Through this, sustainable tourism displays its positive role in protection of species diversity and therefore poverty is alleviated and the sustainable development will occur [2].

Types and scope of environmental effects of tourism closed depend on types, the density and the expansion of tourism. Researchers like Pigram (1980), and Travis (1982) indicated the significance of the environmental effects of tourism [3]. Naming some Iranian studies in this field, the works of Rezvani on the role of ecotourism in protection of environment [4]: Karim conducted a research on geographical and ecological effects of costal tourism and sustainable development [5] and Alizadeh examined the impact of tourists' presence on ecological resources in the villages of Torghabeh in Mashhad [6].

\section{Methodology}

In the present research, first the concept of sustainable development and different dimensions of relationships between the environment and tourism as well as species diversity was examined. Second, the positive and negative effects of tourism industry on the environmental condition in the study area were evaluated and finally, existing strengths and shortcomings in the region for tourism attractions were taken into consideration. Moreover, the climate data of the region, geographical features and day and night climatetourim conditions of Semnan using the indexes like comfort index of Olegi were measured. To do this, maximum and minimum temperature, and relative humidity during a ten year period were used.

\subsection{Sustainable Development and Tourism Planning}

Today's, tourism has been recognized as one of the most profitable industries in the world and many countries have been struggling to exploit from tourism industry as much as they can. The economic benefits of this industry are considerable to extent that includes approximately $7 \%$ of the world capital [7]. Currently, all countries either developed or under developing or undeveloped have agreed that any development takes place only through planning. Thus, the effective factors on the development prices are divided into two categories as:

1) Natural factor: climate, geographical location, area, access to sea.

2) Human factors: population, economic system, social system, technology [8].

Generally speaking, planning can resolve conflicts may be created in the prices of development. Development of tourism in one hand can leave positive economic, social, cultural and environmental benefits in the tourist society and on the other hand may bring some negative effects in all aspects especially the ecological aspect. In fact, the tourism industry is an integration of different activities, services and industries, thus it contains some special elements are divided into two general categories:

1) Tourism resources: including natural, cultural, historical, and human resources that they individually make various forms of tourism. 2) Infrastructures: refer to all infrastructural and super structural constructs of the country and generally contain communication, health, transportation systems, hotels, restaurants, shopping centers, recreation centers etc. [9]. Figure 1 shows sustainable urbanism infrastructure and Figure 2 shows the process needed to achieve this.

\subsection{Interrelationships of the Environment and Tourism}

Turning the new century, fundamental structures of communities have been revolutionized and illogical exploitation of the nature has forced man to look more precisely at the disaster of excessive exploitation of the nature and has moved him to plan more comprehensively and appropriately in this regard. Then, it finds a solution for protection of the environment in one hand and a safe exploitation from the nature.

However, the first scenario in this situation is to trust the local for protection and improvement of ecotourism in any country and using their help the nature will be reserved and the existing facilities in the region will be 


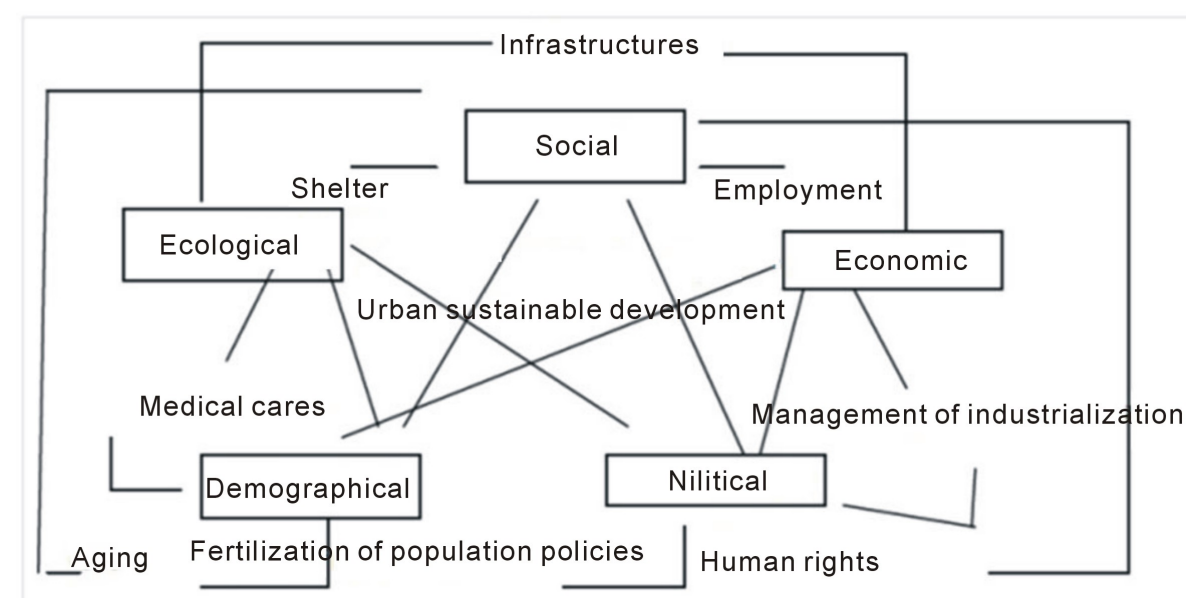

Social: the main part

Shelter: topic

Figure 1. Sustainable urbanism: main parts and the significant subjects.

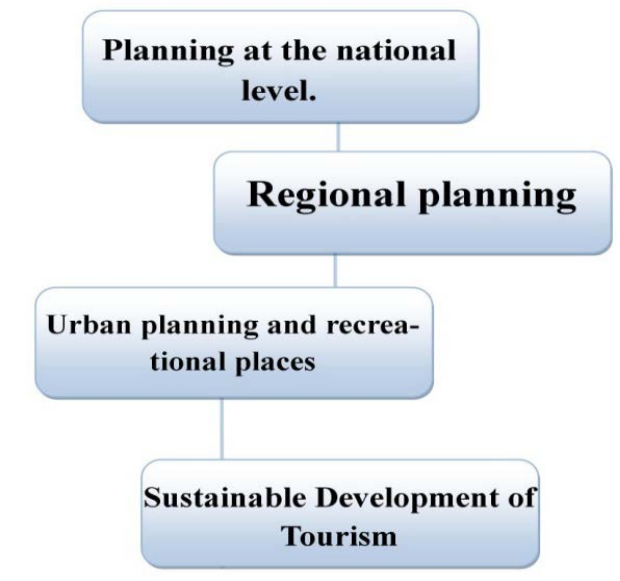

Figure 2. The process of planning for achieving to sustainable development of tourism.

properly identified. The second solution is to inform the local to back the nature and use it correctly. As a matter of fact, a relationship exists between tourism and the ecology in three forms as following:

1) Some forms of physical ecology are tourists' attractions.

2) Expansion of tourism and use of tourists from one specific place will leave environmental effects.

3) Facilities and infrastructures of tourism make a part of created environment.

The tourism activities also can establish plans contribute to protection of the environment. Therefore, we see that tourism is able to interact with the environment in different forms and takes outstanding steps in preserving the environment. Some of these effects are listed below.

- Tourism can make a flow of coming and going to the attractions ad does some activities for supporting ad managing these areas.

- Tourism can attract the public attention to historical and ancients attractions and helps to perform preservation and reconstruction plans for these places with association of investors.

- Tourism absorbs the public attention to the species diversity specially the endanger ones.

- thanks to significance of sun rise as one of tourist attraction and motives, this phenomenon can display the 
risk of resorption and loss of ozone layers and force planners and decision makers to do activities in this regard.

- The established infrastructures for the tourism industry are beneficial for the local as well. They are railroads, roads, airports etc.

- Tourism provides opportunity, and ground for preservation and maintenance of traditional transportation systems, old steam trains and ships that is a strategy for proper saving and exploitation.

Tourism can act efficiently in development, modernization, and beautification of the industrial places, mines and sea shores that have been abandoned for years after the exploitation period [10]. Therefore, due to plan for tourism considering the environment, understanding the effects of tourism on the environment will be the very first important problem [11].

\subsection{Introduction of the Study Region}

The city Semnan is located between three cities of Damghan, Garmsar, and Mehdishahr at longitude 53 degrees and 23 minutes and at latitude 35 degrees and 34 minutes. The average height above sea level is $1130 \mathrm{~m}$. The distance to the city Tehran is $216 \mathrm{~km}$, and it is connected to the transcontinental railroad Tehran-Mashhad [12]. The climate in summer is hot and dry and winter is relatively cold. Rainfall occurs in the cold season and the average annual rainfall is $140 \mathrm{~mm}$. The average annual temperature is $7.17^{\circ} \mathrm{C}$, while the absolute maximum temperature is $5.44^{\circ} \mathrm{C}$ and absolute minimum is $-4.6^{\circ} \mathrm{C}$. The seasonal river of Roudbar is located on northwest of the city that originates from the Alborz mountains and crosses the city Mehdishahr puts into Dasht-e Kavir [13]. Location in respect other cities is shown in Figure 3.

\subsection{Tourist Attractions of the Region}

As a historical city, Semnan is located on the road to the famous Silk-Road and has lots of historical and cultural attractions represent the rich culture and ancient history in the region. Of the most significant attractions are Darband cave, the historical house of Tadayon, the Rajabi house, Pahneh bath that has been used as museum currently, historical timcheh of Pahneh, the Arg gate, the great mosque, the Imam mosque. and the Imam mosque. Some historical and cultural elements of the city Semnan is referred in Table 1.

\section{Analysis Climate Tourism (Climatourism) of Semnan}

One of the most significant factors in relation to standards of a good life is taking into consideration the quality of comfort properties in the place. The human ecology depends greatly to the thermal equilibrium of man's body temperatures with the environment temperature. The ecological comfort equilibrium happens only when the balance between absorption and desorption temperature of the skin and surrounding environment is created and makes Ronnie body temperature fix at $37^{\circ} \mathrm{C}$ [13]. To assess these indexes, the data of years 1982-2004 were extracted from the synoptic station of the city Shown in Table 2.

\subsection{The Gioni Diagram}

In 1969 Gioni introduced the bioclimatic diagram of buildings. This diagram clearly shows the comfort zone of the man in relation to humidity and temperature. In fact, different buildings and living in the, do not provide comfort in a way that the comfort conditions inside the building is measured via a diagram named eco-building. For instance, the results of computations indicate that in March during the day time buildings are heated via sun temperature, but in at night there is no need to heating instruments [14]. Other results are shown in Figure 4.

\subsection{Olegi Comfort Diagram}

Using the climate comfort diagram (Olegi), it would be possible to determine duration of annual cold and heat of different cities and regions and to see how much extreme the thermal conditions of different areas are. Then through these results we can specify a mechanical system and rate of the need each residential building may have in terms of humidity, heat and cold air [15]. Other results are shown in Figure 5.

\section{Conclusion}

In Semnan, proper conditions are available for use of natural energy to provide climate comfort and through 


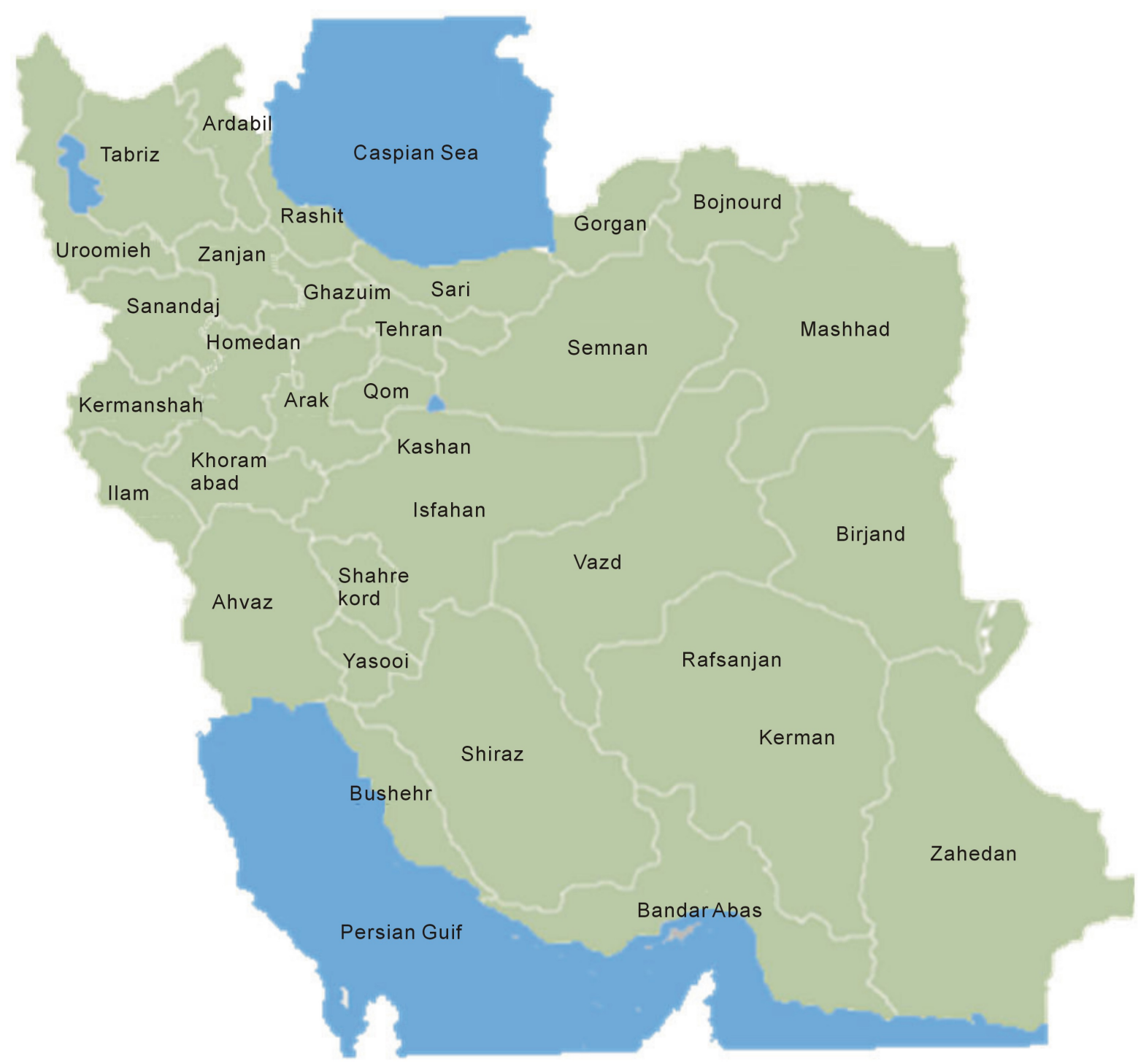

Figure 3. Geographical location of Semnan city.

Table 1. Historical and cultural elements of the city Semnan.

\begin{tabular}{cc}
\hline Mosques & Tourist attractions of Semnan \\
$\begin{array}{c}\text { Government sites and } \\
\text { castles } \\
\text { Caravanserais } \\
\text { Shrines }\end{array}$ & $\begin{array}{c}\text { Mosque Zavqan-Imam (Shah) Mosque-Semnan minaret of the grand mosque } \\
\text { Gate of Semnan citadel-building capital (Aboozar Field)-Zavqan castle-ancient fortress, } \\
\text { fort-Fort parchment }\end{array}$ \\
$\begin{array}{c}\text { Tomb } \\
\text { Markets }\end{array}$ & $\begin{array}{c}\text { Hahya ibn Musa al Shrine-Shrine of Ali ibn Ja'far-Shrine of Ali ibn Ashraf-Sir Sar Tomb-Tomb } \\
\text { of the Prophets }\end{array}$ \\
Bath & Grand market of Semnan-Sheikh Alaa al Doleh Market \\
& Across bath-bath Nasar-Bath Ghelli \\
\hline
\end{tabular}

proper designing of direction and intensity of sun light, type of materials, efficient use of windows etc. create appropriate use of natural energies and prevention from waste of energy and decrease of costs related to the heat and cold. The equilibrium state of ecological comfort occurs only when the balance between absorption and de- 
Table 2. Architecture compatible with climate condition for the gioni index.

\begin{tabular}{ccc}
\hline & segment & Architecture ruling \\
\hline 1 & $1-3,8-25$ & Thermal exchange must be reduced through building walls \\
2 & $1-3,22-25$ & To prevent from air penetration from windows and inconvenient joints. \\
3 & $4-25$ & Sun heat must be minimized as much as possible \\
4 & $1-3$ & The sun heat must be exploited. \\
5 & $8-13$ & The cross ventilation (curran) have to used for rooms. \\
6 & $18-20,15-16,13,9-10$ & Cooling due to evaporation of surface \\
7 & $12-19,9-10$ & Using cooling from long wave radiation-induced wall heat \\
9 & $21-23$ & Using from mechanical cooling system \\
10 & 22 & Using \\
from mechanical cooling system and dehumidifier
\end{tabular}

\section{Table 3. Comfort and tourism conditions in Semnan.}
No.
Month
Comfort conditions of tourism and ecology protection

1

2

3

4

5

6

7

8

9

10

11

12
April

May

June

July

August

September

October

December

November

January

February

March
In March there is no need to use of fossil energy and there is comfort inside and outside the buildings, therefore it is a good time for tourism in harmony with the environment.

During day there is no need for heating, the comfort is possible and use of natural ventilation is good. Somewhat appropriate for tourism, taking into account the requirements and installations is proper.

In June the need for fossil fuel and produce no pollution and natural conditions for tourism is in harmony with the environment

In August, the energy required to cool the air at night is not on iodine physical tools used in creating comfort and energy consumption

On the use of natural ventilation air can be brought into the comfort zone, and at night there is no need to heating appliances.

In most cases, using the sun's heat can be secured from the house, but at night it can be used to heat items. In late November, the comfort zone is located in tourism due to fossil fuel use and energy use will be in harmony with the environment

There was a sense of comfort and indoor use heat sources are necessary. Outside of the building is very cold weather and atmospheric conditions governing tourism facilities and no visit would be

There was a sense of comfort and indoor use heat sources are necessary. There are therefore fossil fuel consumption and pollution in the environment.

Very cold air outside buildings and tourist facilities and no visit would be the dominant atmospheric conditions.

There was a sense of comfort and indoor use heat sources are necessary. Exploitation of fossil fuels and energy this month is high and will cause pollution of tourism.

Very cold air outside buildings and tourist facilities and no visit would be the dominant atmospheric conditions

Due to the thermal comfort zone to heat environment and fossil fuel heating appliances need to be warm and outside the building envelope is required. Meanwhile, in late March of air stiffness lessens and comfort is provided. 


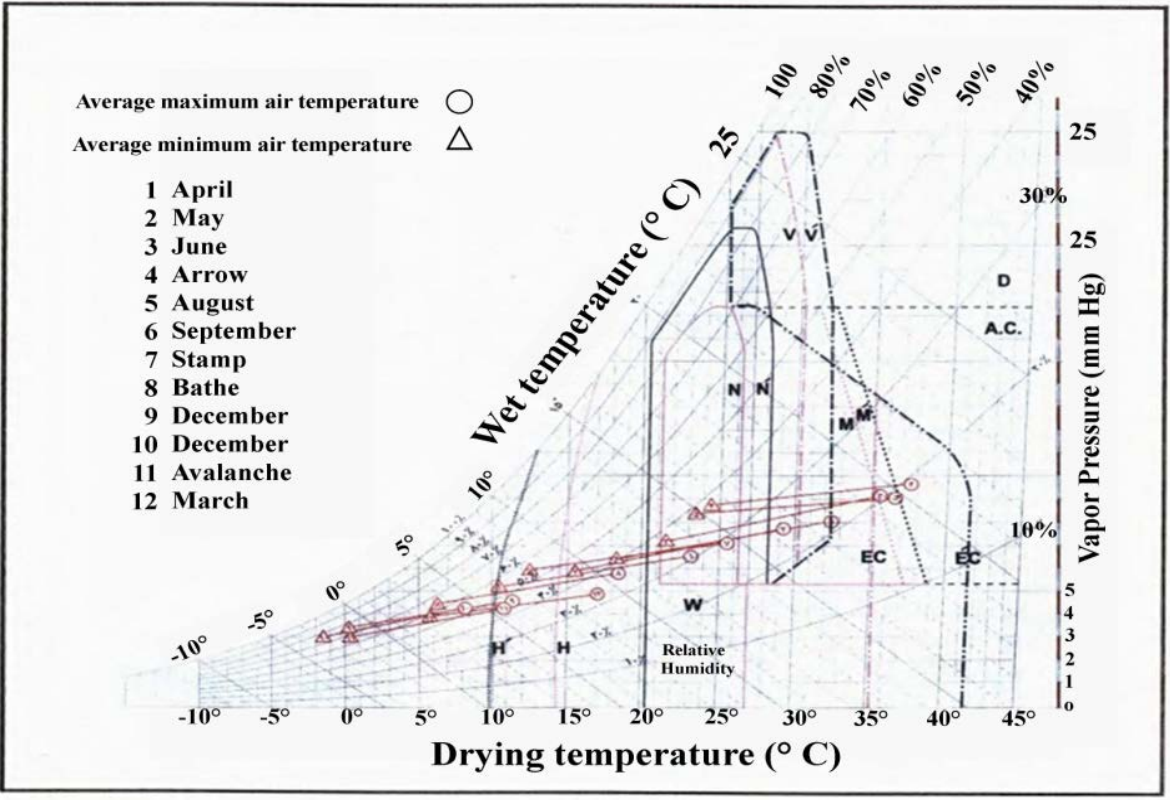

Figure 4. the bioclimatic diagram (Gioni ) for Semnan city during statistical period.

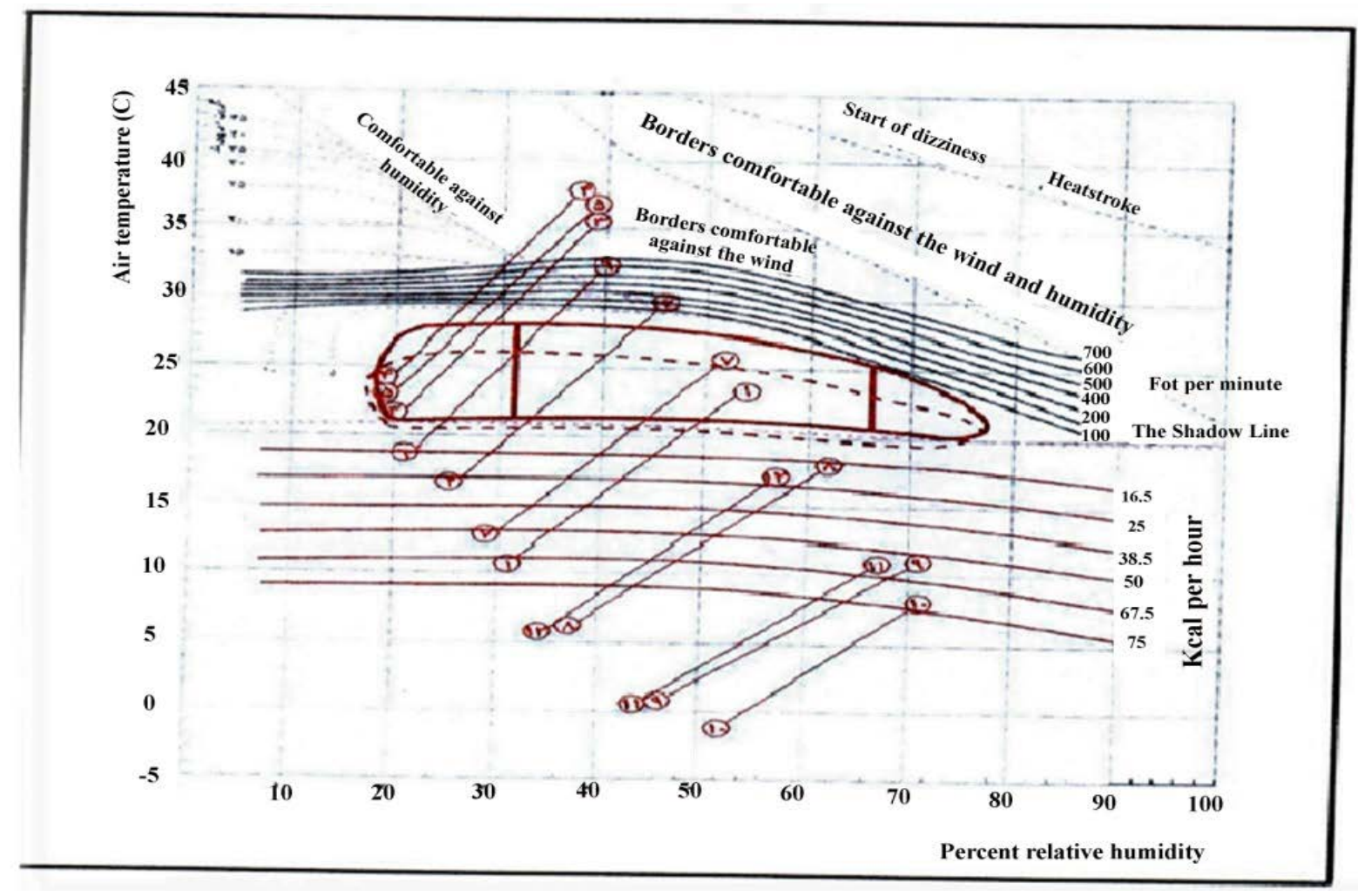

Figure 5. Drawing the Olegi comfort diagram in Semnan.

Sorption. Temperature of the skin and surrounding environment is created and makes Ronnie body temperature fixed at $37^{\circ} \mathrm{C}$ [13]. The climate conditions of the region also affect the architecture style and the type of materials directly. All principles of sustainable development have to be embodied in a full process that leads to establishment of a healthy environment [7]. Comfort and tourism conditions in Semnan are referred in Table 3. 


\section{References}

[1] Deputy of Economic Planning and Affaires, Evaluation of Tourism in Iran and Islamic Countries.

[2] www.chtn.ir/Webforums/Fa/Article/ArticleInfo.apx?ID=1859

[3] Edward, I. (1999) Tourism Planning: An Integrated and Sustainable Development Approach. VNR Tourism and Commercial Recreation Series, 208.

[4] Rezvani A.A. (2001) The Role of Ecotourism in Protection of the Environment. Journal of Environmental Studies, 115-122.

[5] Karimi, T. (2004) Geographical and Ecological Effects of Coastal Tourism and Sustainable Development. Education Office of Abhar, Abhar, 1-18.

[6] Alizadeh, K. (2003) The Impacts of Tourists on the Environmental Resources, Case Study: Torghabeh District in Mashhad. Journal of Geographical Researches, 35, 55-70.

[7] Goharian, M.A. and Ketabchi, M. (2005) International Tourism. Amir Kabir Publication, Tehran.

[8] Zerang, A. (20060 Geographical Properties of the Developed Countries. Islamic Azad University, Tehran/

[9] Shadi, M.A. (2008) Transportation the Missing Link. Journal of Terminals of the Municipalize,

[10] Batra, G.S. and Chawla, A.S. (1995) Tourism Management, A Global Perspective: Department of Business Management. Deep \& Deep Publication, New Delhi, 95-96.

[11] Ranjbarian and Zahedi (2000) Tourism Planning in the Local and National Scale. World Tourism Organization.

[12] Jankens, C. (1995) Translated by Farhad Mortezaei. Marandiz Publication, Tehran.

[13] Golparvar, N. (2008) Man, Nature and Architecture. Jahan Hele, Tehran.

[14] Kasmaei, M. (1984) Climate and Architecture, Center for Housing Researches, 20.

[15] Kasmaei, M. (1989) Zoning and Guide for Climate Designing: Dry and Hot, Center for Housing Researches. 